\title{
Inflammatory Pseudotumor and Sarcoma of Urinary Bladder: Differential Diagnosis and Outcome in Thirty- Eight Spindle Cell Neoplasms
}

Kenneth A. Iczkowski, M.D., Jonathan H. Shanks, M.D., Virgil Gadaleanu, M.D., Liang Cheng, M.D., Edward C. Jones, M.D., Roxann Neumann, R.N., Antonio G. Nascimento, M.D., David G. Bostwick, M.D. Departments of Pathology and Laboratory Medicine of the University of Florida and Veterans Administration Medical Center (KAI), Gainesville, Florida, Christie Hospital (JHS), Manchester, United Kingdom, University of Malmö (VG), Malmö, Sweden, Indiana University (LC), Indianapolis, Indiana, Vancouver General Hospital (ECJ), Vancouver, B.C., Canada, Mayo Clinic (RN, AGN), Rochester, Minnesota, University of Virginia (DGB), Charlottesville, Virginia, and Bostwick Laboratories (DGB), Richmond, Virginia

We assessed diagnostic criteria among 38 spindle cell tumors of the urinary bladder and obtained follow-up in 36 patients. Patients comprised 28 males and 10 females aged 2.5 months to 87 years. Hematuria was the commonest presenting symptom (27 patients). After review and immunohistochemical workup, 17 patients had inflammatory pseudotumor (myofibroblastic tumor), 4 postoperative spindle cell nodule, 1 leiomyoma, 13 sarcoma (7 low-grade; 6 high-grade), and 3 carcinoma. Mean age was 38 years for pseudotumor (range 15 to 74), 65 for postoperative spindle cell nodule, 51 for sarcoma, and $\mathbf{7 6}$ for carcinoma. Size of pseudotumor averaged $4.4 \pm 0.7 \mathrm{~cm}$ (range 1.5 to 13.0 ), similar to sarcoma, $4.0 \pm 0.6 \mathrm{~cm}$ (range 0.5 to 7.0 ). Similar proportions of benign tumors and sarcomas had muscularis propria invasion. The criteria that best differentiated sarcoma from inflammatory pseudotumor were presence of necrosis at the tumordetrusor muscle interface in muscle-invasive cases, and nuclear atypia. Sarcoma also had less prominent microvasculature, less variable cellularity, consistently $\geq 1$ mitotic figure per 10 high-power fields, and predominant acute inflammation without plasma cells. p53 protein nuclear immunostaining was moderate, unlike the rare to absent staining in pseudotumors. Because all 12 sarcomas were desmin-negative, we did not call them leiomyosarcoma; they overlapped with benign tumor in epi-

Copyright (C) 2001 by The United States and Canadian Academy of Pathology, Inc.

VOL. 14, NO. 10, P. 1043, 2001 Printed in the U.S.A

Date of acceptance: May 10, 2001.

Address reprint requests to: Kenneth A. Iczkowski, M.D., Pathology and Laboratory Medicine Service (113), VA Medical Center, 1601 S.W. Archer Road, Gainesville, FL 32608-1197; e-mail: iczkoka@pathology.ufl.edu; fax: 352-379-4023. thelial, mesenchymal, and actin immunostaining. Among 12 sarcoma patients, 2 died of tumor (at 3 months). Two of four experienced tumor recurrence after partial cystectomy ( 2 and 26 months). No pseudotumors recurred after transurethral resection or partial cystectomy, although one patient, 5 months after transurethral resection, had histologically identical pseudotumor that the surgeon considered residual. Another patient with pseudotumor, not a candidate for tumor ablation after transurethral resection, had continued tumor growth and he died of urosepsis. In conclusion, inflammatory pseudotumor, although overlapping with sarcoma in presentation, age range, and size, does not metastasize and remains histologically distinct from low-grade sarcoma.

KEY WORDS: Inflammatory pseudotumor, Leiomyosarcoma, Myofibroblastic tumor, Postoperative spindle cell nodule, Spindle cell tumor, Urinary bladder.

Mod Pathol 2001;14(10):1043-1051

Inflammatory pseudotumor (IP) or myofibroblastic tumor was first recognized in the lung. Presently, extrapulmonary examples of this tumor have been described in virtually all major organs. IP was initially considered nonneoplastic, representing an aberrant inflammatory response despite its gross and microscopic features of a spindle cell neoplasm. Some cases expressed viral genomes (1) and many were accompanied by the constitutional symptoms of an inflammatory process (fever, anemia, weight loss), which resolve after surgical resection. Tumor necrosis factor $\alpha$ may promote fibroblast proliferation and the constitutional symptoms characteristic of most IP (2). However, the hypoth- 
esis that IP is reactive in nature with a pathogenesis related to cytokine release applies more readily to cases in the lung than in extrapulmonary sites of involvement. Several pathologic aspects of IP are neoplastic and unlike a purely inflammatory process: it has the potential for local recurrence; multifocal, noncontiguous tumors may develop; local growth is infiltrative; vascular invasion is possible; and five IP at various sites-lung, soft tissue, and bone-were clonal $(3,4)$ and had aberrant karyotypes (3). From a prognostic perspective, therefore, one can speculate that IP is a soft tissuemesenchymal tumor of indeterminate or low malignant potential.

The histologic diagnosis of IP of the bladder is difficult owing to its relative rarity and a spectrum of mimics, including leiomyoma and leiomyosarcoma. It is diagnosed in the absence of prior surgery (5) and is thought to have female and young adult preponderances (6). The term postoperative spindle cell nodule (PSCN) of the bladder has been applied to those lesions histologically similar to IP that develop within 3 months of a surgical procedure (7). Distinction of these entities from lowgrade inflammatory leiomyosarcoma or fibrosarcoma is particularly vexing, and some pathologists have questioned the existence of IP in the bladder. To our knowledge 81 cases of IP have been described in the bladder, of which 26 included patient follow-up (8-14). The clinicopathologic criteria for separating IP and PSCN from leiomyosarcoma deserve further exploration. Further, most reported cases of IP have been completely excised, so the outcome after partial resection is not known. Consequently, the untreated natural history of IP of the bladder is uncertain. Our report includes the first follow-up of an incompletely resected IP in which further treatment was precluded.

\section{PATIENTS AND METHODS}

We searched the in-house and consultation files of Mayo Clinic, 1928-1998; Christie Hospital, 1982-1999; Vancouver Hospital, 1997-1999; and Bostwick Laboratories, 1999, for all spindle cell bladder tumors; two cases were added from Reading (PA) Hospital and Gainesville (FL) VAMC. All cases but one (12) were not previously reported. The inclusion criterion for inhouse cases was the observation by DGB, AGN, JHS, EJ, or LC of focal findings suggestive of IP/PSCN, or mention of those entities in the differential diagnosis (regardless of final diagnosis). The inclusion criterion for outside cases was that the referring pathologist considered the diagnosis of IP or PSCN. Three patients with sarcoma were excluded because the sarcoma did not originate from the bladder, and two because the tumor was indeterminate owing to poor tissue preservation. Remaining were 38 patients, only one of whom was previously reported (12). Patients ranged in age from 2.5 months to 87 years; 28 were male and 9 female. Histologic data were tabulated and distinguished IP and PSCN from sarcoma (see Results). PSCN, rather than IP, was diagnosed if histologically benign tumor arose at any interval after prior bladder instrumentation or surgery. Slides were reviewed by DGB, VG, and KAI to confirm all diagnoses. Spindle cell carcinoma was diagnosed only if associated with a definite invasive or in situ urothelial carcinoma component, regardless of immunostaining. The 1997 TNM system was used for T staging (15); any case without evaluable muscularis propria was stage "indeterminate." Counts were made of mitotic figures per 10 high-power $(0.6 \mathrm{~mm}$ diameter $)$ fields (hpf) and inflammatory cells per hpf. Immunohistochemical stains were performed in most cases, using the automated LSAB/Ventana ES (Tucson, AZ), as follows: Keratin (AE1/AE3) Boehringer Mannheim, Indianapolis, IN, primary dilution 1/400; EMA (E29), DAKO, Carpenteria, CA, 1/100; Vimentin (3B4), DAKO, $1 / 500 ; \alpha$-smooth muscle actin (1A4), DAKO, 1/150; Muscle-specific actin (HHF35), DAKO, 1/50; Desmin (Der 11), DAKO, 1/100, p53 protein (Ki67), DAKO, $1 / 100$. Staining was evaluated as to intensity $(0$ to $3+$ ) and percent of counted cells positive (0 to $100 \%$ ). Follow-up was obtained up to March 2001 for 36 of 38 patients, by corresponding with either the patient at home or the patient's surgeon.

\section{RESULTS}

\section{Presentation and Demographics}

Presenting symptoms were known for 36 patients, and included hematuria in 27 , obstruction in 11, and bladder calculi in 2 (Table 1). Two of the patients with PSCN were asymptomatic. After review of all cases and immunohistochemical stains in 30, 22 were diagnosed as benign (16 IP, 5 PSCN, 1 leiomyoma); 13 were diagnosed as sarcoma (7 low-grade; 6 high-grade), and 3 as carcinoma. All 20 patients with IP, PSCN, or leiomyoma were initially diagnosed correctly. Four of 13 patients with sarcoma had been misdiagnosed by referring institutions: three with IP and one with carcinosarcoma.

Mean patient age was 38 years (15 to 74 ) for IP, 65 (49 to 83) for PSCN, 51 (0.2 to 87) for sarcoma, and 76 (69 to 83) for carcinoma/carcinosarcoma. Eleven IP patients were men and six were women. Possible predisposing conditions included neurogenic bladder secondary to cerebrovascular accident in Patient 2 with IP. All patients with PSCN had undergone bladder biopsy/transurethral resection, up to 13 months (Case 21) preoperatively. No sarcoma patients had prior cytoscopy; Patient 30 with sarcoma had pos- 
TABLE 1. Clinical Data in 38 Patients with Spindle Cell Tumor of Bladder; 21 with Bladder Inflammatory Pseudotumor/Postoperative Spindle Cell Nodule, and 17 with Other Spindle Cell Tumors

\begin{tabular}{|c|c|c|c|c|c|c|c|c|}
\hline Patient & Age (yr) & Sex & $\begin{array}{c}\text { Prior Bladder Instrumentation } \\
\text { or Pathology }\end{array}$ & Symptoms & Size $(\mathrm{cm})$ & T Stage & Therapy & Postoperative Follow-Up \\
\hline \multicolumn{9}{|c|}{ Inflammatory pseudotumor } \\
\hline 1 & 27 & $\mathrm{~F}$ & None & mHemat., irrit. & 4.0 & 2 & TUR & NET-21 mo \\
\hline 2 & 48 & M & $\begin{array}{l}\text { Neurogenic bladder following } \\
\text { CVA }\end{array}$ & Hemat., obstr. & 2.5 & 2 & $\mathrm{PC}$ & NET-5 mo \\
\hline $3^{a}$ & 74 & M & None & Hemat., obstr. & 13.0 & 1 & TUR & $\begin{array}{l}\text { Tumor } 5 \text { mo later grew to } 37.5 \\
\mathrm{~cm} \text {; died of urosepsis }\end{array}$ \\
\hline 4 & 28 & $\mathrm{~F}$ & None & Obstr. & 8.5 & 2 & $\mathrm{PC}$ & NET-3.2 yr \\
\hline 5 & 16 & $\mathrm{~F}$ & None & Hemat. & 3.3 & 1 & $\mathrm{PC}$ & NET-9.5 yr \\
\hline 6 & 25 & M & None & mHemat. & 3.5 & 2 & TUR & NET-4.7 yr \\
\hline $7^{a}$ & 26 & M & None & Hemat. & 7.0 & 2 & TUR & $\begin{array}{l}3 \mathrm{~cm} \text { of residual tumor at } 5 \mathrm{mo} \text {; } \\
\text { NET after } 8 \mathrm{mo}\end{array}$ \\
\hline $8^{a}$ & 15 & $\mathrm{M}$ & None & Hemat., irrit. & nd & 2 & TUR & NET-22 mo \\
\hline 9 & 16 & $\mathrm{M}$ & None & mHemat. & 2.5 & 2 & TUR, PC & NET-6 mo \\
\hline 10 & 36 & $\mathrm{M}$ & None & Hemat. & 3.0 & 2 & TUR & no data \\
\hline $11^{a}$ & 35 & $\mathrm{~F}$ & None & Hemat. & 4.0 & 1 & TUR & NET-5 mo \\
\hline $12^{a}$ & 43 & $\mathrm{M}$ & None & Hemat. & 4.0 & 2 & TUR, PC & NET-2.2 yr \\
\hline 13 & 50 & $\mathrm{M}$ & None & mHemat. & 6.0 & 2 & TUR & NET-2.2 yr \\
\hline 14 & 72 & $\mathrm{~F}$ & $\begin{array}{l}\text { DM, Enterococcal cystitis; } \\
\text { synchronous juxtatumoral } \\
\text { low-grade urothelial ca. }\end{array}$ & Hemat., obstr. & 4.0 & ind. & TUR & $\begin{array}{l}\text { Low grade urothelial ca. at } 1 \\
\text { mo; NET-10 mo }\end{array}$ \\
\hline $15^{a}$ & 50 & $\mathrm{M}$ & None & Hemat. & 1.5 & 2 & TUR & NET-5.5 yr \\
\hline $16^{a}$ & 33 & $\mathrm{~F}$ & None & Irrit. & 1.3 & 2 & PC & NET-11 yr \\
\hline 17 & 44 & M & $\begin{array}{l}\text { TUR, Low-grade uro. ca. } 6 \text { yr } \\
\text { prior }\end{array}$ & nd & 2.5 & 2 & PC & NET-6 yr \\
\hline \multicolumn{9}{|c|}{ Postoperative spindle cell nodule } \\
\hline $18^{a, b}$ & 49 & M & Biopsy (benign) 2 mo prior & Hemat. & 3.0 & 2 & PC & $\begin{array}{l}\text { CIS of bladder } 12 \mathrm{mo} \\
\text { postoperative }\end{array}$ \\
\hline 19 & 83 & $\mathrm{M}$ & TUR papilloma 1 wk prior & Hemat. & 1.7 & 2 & TUR & NET-8.5 mo \\
\hline 20 & 56 & M & $\begin{array}{l}7 \text { prior biopsies, low-grade } \\
\text { uro. ca. } 5 \text { mo prior }\end{array}$ & None & 0.8 & ind. & TUR & NET-2.5 yr \\
\hline 21 & 70 & M & $\begin{array}{l}13 \text { TURs-high-grade uro. ca. } \\
23 \mathrm{yr} \text { to } 13 \text { mo prior }\end{array}$ & None & 0.4 & ind. & TUR & NET-2.2 yr \\
\hline \multicolumn{9}{|c|}{ Leiomyoma } \\
\hline 22 & 52 & $\mathrm{~F}$ & None & Hemat. & 5.0 & ind. & TUR & NET-11 mo \\
\hline \multicolumn{9}{|c|}{ Sarcoma, low-grade } \\
\hline 23 & 53 & $\mathrm{~F}$ & None & Hemat. & 0.5 & 2 & PC & NET-30.2 yr \\
\hline 24 & 46 & $\mathrm{M}$ & None & nd & nd & 2 & $\mathrm{Bx}, \mathrm{RT}$ & NET-35.6 yr \\
\hline 25 & 66 & $\mathrm{M}$ & None & Hemat. & 2.5 & 2 & $\mathrm{Bx}, \mathrm{PC}$ & NET-9.9 yr \\
\hline 26 & 0.2 & M & None & Obstr. & 3.0 & 2 & PC, then RC & Recurred 26 mo, NET-48.5 yr \\
\hline 27 & 72 & $\mathrm{M}$ & None & Hemat., obstr. & nd & 3 & $\mathrm{Bx}, \mathrm{RT}$ & Died of tumor-3 mo \\
\hline 28 & 38 & $\mathrm{M}$ & None & Hemat. & 4.0 & 2 & PC, then RC & NET-3.4 yr \\
\hline 29 & 87 & M & None & Hemat., obstr. & 6.0 & ind. & $\mathrm{PC}$ & $\begin{array}{l}\text { Recurred } 2 \text { mo; died-unknown } \\
\text { cause } 5 \text { mo }\end{array}$ \\
\hline \multicolumn{9}{|c|}{ Sarcoma, high-grade } \\
\hline 30 & 4.1 & $\mathrm{M}$ & Posterior urethral valves & Irrit., obstr. & 7.0 & ind. & $\mathrm{Bx}, \mathrm{RT}$ & Died of tumor- 3 mo \\
\hline 31 & 84 & $\mathrm{M}$ & None & Calculi & 4.0 & ind. & TUR & No data \\
\hline 32 & 68 & $\mathrm{M}$ & None & Hemat. & 2.5 & 1 & $\mathrm{RC}$ & $\begin{array}{l}\text { NET-1 mo; died-unknown } \\
\text { cause }\end{array}$ \\
\hline 33 & 57 & $\mathrm{~F}$ & None & Hemat., obstr. & 3.0 & 2 & $\mathrm{RC}$ & NET-6 yr \\
\hline 34 & 36 & $\mathrm{M}$ & None & Hemat., obstr. & 4.0 & 2 & RC & NET-5 yr \\
\hline 35 & 49 & M & $\begin{array}{l}\text { RT for rectal ca. resected } 13 \\
\text { mo prior }\end{array}$ & Calculi & 7.0 & ind. & PC & NET-23 mo \\
\hline \multicolumn{9}{|c|}{ Carcinoma } \\
\hline 36 & 83 & $\mathrm{~F}$ & TUR, bx. & Hemat. & 3.0 & 2 & $\mathrm{Bx}$ & Died of tumor-2 mo \\
\hline 37 & 77 & M & $\begin{array}{l}\text { TUR, CIS and pelvic CLL, } 7 \text { yr } \\
\text { prior }\end{array}$ & Hemat. & nd & ind. & $\mathrm{RC}$ & Died of CLL, $3.5 \mathrm{yr}$ \\
\hline 38 & 69 & $\mathrm{M}$ & $\begin{array}{l}\text { Coexistent, noninvasive uro. } \\
\text { ca. }\end{array}$ & Obstr. & 5.0 & ind. & PC & $\begin{array}{l}\text { CIS at } 2 \text { mo; noninvasive } \\
\text { urothelial ca. } 14 \text { mo }\end{array}$ \\
\hline
\end{tabular}

${ }^{a}$ Electron microscopy performed.

${ }^{b}$ Mitotic rate elevated to $15 / 10$ high-power fields in this tumor.

Bx, biopsy; CVA, cerebrovascular accident; CIS, carcinoma in situ; CLL, chronic lymphoid leukemia; DM, diabetes mellitus; Hemat., gross hematuria; mHemat., microscopic hematuria; ind., indeterminate stage, no muscularis propria; Irrit., irritation; nd, no data; NET, no evidence of tumor; Obstr., obstruction; PC, partial cystectomy; RC, radical cystectomy; RT, radiotherapy; TUR, transurethral resection.

terior uretral valves, and Patient 35 had undergone radiotherapy for rectal carcinoma. Both synchronous and metachronous urothelial carcinoma occurred in one patient with IP (Patient 14); prior or subsequent urothelial carcinoma or papilloma occurred in all four patients with PSCN, and none with sarcoma. No patient with sarcoma, and two of three with carcinoma/ carcinosarcoma had prior instrumentation. 
Tumor size of IP averaged $4.4 \pm 0.7 \mathrm{~cm}$ (range 2.5 to 13.0), PSCN was $1.5 \pm 0.6 \mathrm{~cm}$ (0.4 to 3.0$)$, and sarcoma was $4.0 \pm 0.6 \mathrm{~cm}(0.5$ to 7.0$)$. Tumor distribution by site within the bladder was nearly identical for 15 benign and 13 malignant tumors in which it was known. Distribution of benign and malignant cases, respectively, was on side walls, 5 and 8; posterior 4 and 4; anterior 2 and 3; dome 3 and 3 ; trigone 1 and 1 .

\section{Treatment and Follow-Up}

Eight of 22 patients with benign tumor underwent partial cystectomy; 14 had transurethral resection only. Four of 13 patients with sarcoma underwent partial cystectomy, 5 radical cystectomy, 3 radiotherapy, and 1 no therapy after transurethral resection. Of three patients with carcinoma/carcinosarcoma, one had partial cystectomy, one radical cystectomy, and one had no further treatment.

Follow-up was available for 36 patients. Among 12 sarcoma patients, 2 had tumor recurrence after partial cystectomy ( 2 and 26 months) and 2 others died of metastatic tumor (at 3 months: 1 low-grade, stage T3, 1 high-grade, stage indeterminate). A man with sarcoma as an infant (Table 1, Patient 25) underwent cystectomy at age 2 , and at age 31 developed a renal abscess, and needed a renal transplant. A 74-year-old man with IP (Patient 3) was not a candidate for definitive tumor ablation after transurethral resection, because of other medical problems (diabetes and hypertension). He experienced an increase in tumor size from 13.0 to 37.5 $\mathrm{cm}$ in 5 months, was not further treated, and died of urosepsis. Another patient (Patient 7) with a transurethrally resected bulky $7-\mathrm{cm}$ IP had a histologically identical $3 \mathrm{~cm}$ tumor, 5 months postoperatively. The surgeon considered this as residual tumor that was initially incompletely resected, rather than as recurrence (E. Martin, M.D., personal communication). No PSCN recurred. One of three spindle cell carcinoma/carcinosarcoma patients died.

\section{Pathologic Findings}

IP was T stage T1 in 3 cases, T2 in 12 cases, and indeterminate in 1. Stage T2 IP, unlike sarcoma, lacked necrosis or myxoid degeneration at the tumor-muscularis propria interface (Fig. 1). Microscopic pattern was biphasic, as in nodular fasciitis. In superficial areas, there was a paucicellular spindle cell proliferation mixed with mostly chronic inflammation, featuring prominent plasma cells (Fig. 2). Only three cases had a sparse component of neutrophils. One case (Patient 8 ) had $20 \%$ eosinophils in the inflammatory infiltrate. Stroma was edematous, acid mucopolysaccharide-rich, with many slit-like blood vessels per low-power field (Fig. 2). The deeper areas of tumor had more densely cellular interlacing storiform fascicles of cells. Cells varied only slightly in size. Larger spindle cells had tapering eosinophilic cytoplasmic processes, normochromatic oval nuclei, and often, visible single nucleoli. Focal nuclear and nucleolar enlargement was attributable to reactive atypia. No cytoplasmic striations or cambium layer were seen, ruling out botryoid rhabdomyosarcoma. There were a mean of 153 chronic inflammatory cells per hpf (range 41 to 412). Mitotic rate was 0 to 1 per 10 hpf in all cases. Ulceration and cystitis were constant findings.

PSCN was stage T2 in three cases and indeterminate in two. Histologically similar to IP, it differed only by the presence of foreign body giant cells and prominent eosinophils in two cases. Mitotic rate was 0 to 1 per $10 \mathrm{hpf}$, except in Case 18, which had 15 per $10 \mathrm{hpf}$. Inflammatory cells per single hpf averaged 140, and in all 4 cases, correlated with postoperative interval: 392 at 1 week but 11 at 13 months. Leiomyoma was like that of the uterus, with no inflammation.

In sarcoma, T2 tumors penetrated deeply into the muscularis (Fig. 3). Low-grade leiomyosarcoma (seven cases) was stage T2 in five cases, T3 in one and indeterminate in one. Spindle tumor cells had moderate nuclear hyperchromasia and atypia (Fig. 4). Mitotic rate ranged from 1 to 16 per $10 \mathrm{hpf}$; intratumoral variation was seen. Coagulative necrosis was seen in all seven cases, and in six T2 or higher cases at the tumor-muscularis propria junction. Myxoid degeneration was noted in two cases, focally with stromal clefts (Fig. 5). Microvasculature was much less prominent than in IP/PSCN. Admixed inflammatory infiltrate was patchy (mean 24 per hpf, range 8 to 44 ) with neutrophils predominating over chronic inflammation in six of seven cases.

High-grade sarcoma (six cases) was stage $\mathrm{T} 1$ in two cases, T2 in one, and indeterminate in three. Growth was infiltrative, with necrosis and in four cases, myxoid degeneration. Cellularity was consistently high, with marked nuclear atypia. Mitotic rate was 0 to 3 per $10 \mathrm{hpf}$, including atypical mitotic figures. The density of inflammatory infiltrate averaged 101 per hpf (range 7 to 280), with acute inflammation predominating in 4 of 6 cases, concentrated at areas of surface ulceration.

Immunohistochemical results (Table 2) were available in 30 cases. p53 nuclear immunostaining was positive in 9 of 11 sarcomas. There was moderate to strong staining of up to $40 \%$ of cells in five low-grade cases and up to $70 \%$ of cells in four high-grade cases (Fig. 6). Two cases were negative; however, they came from 1928 and 

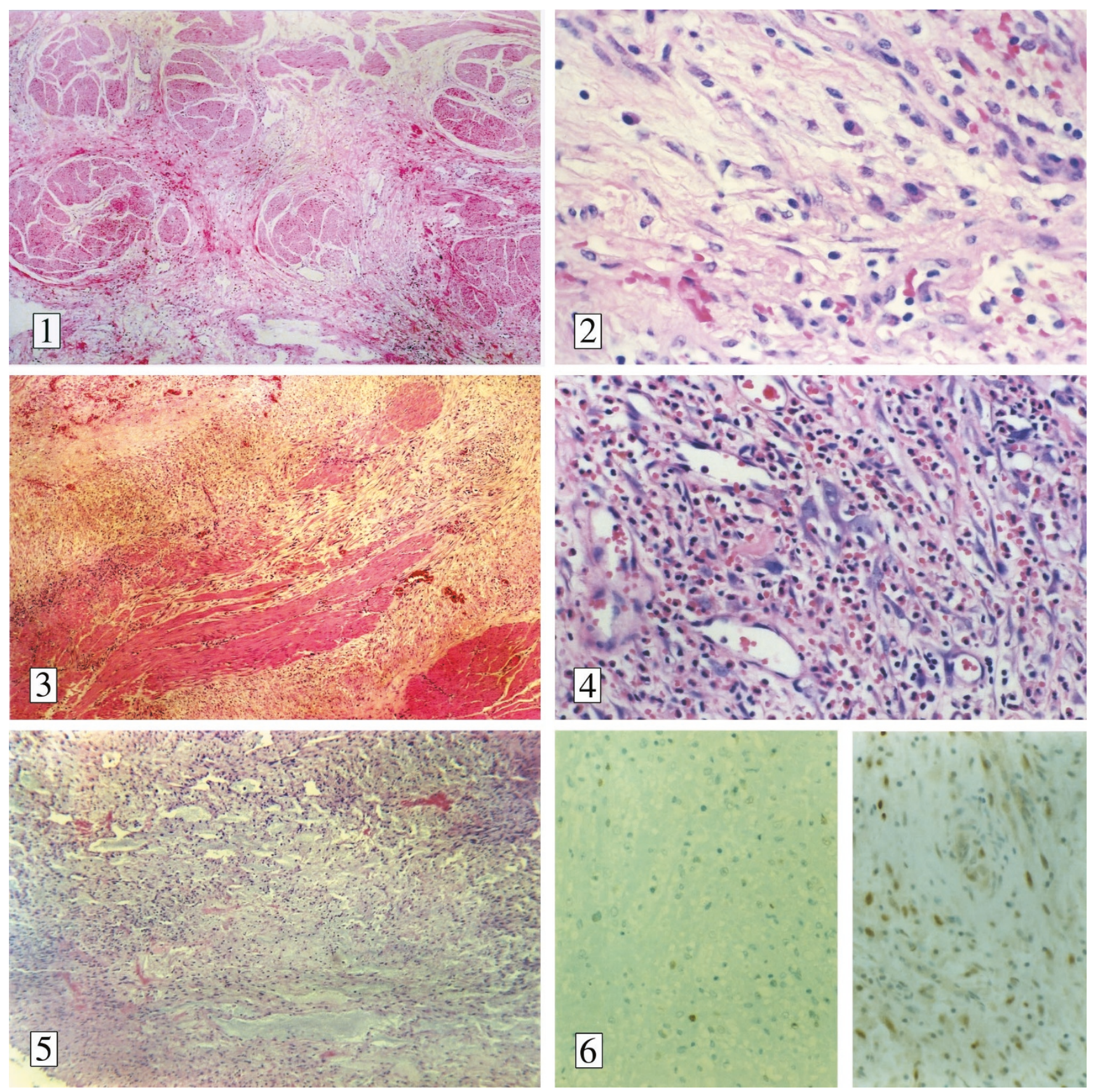

FIGURE 1. Inflammatory pseudotumor in 28-year-old woman (Patient 4). Spindle cells without atypia are amid many stromal microvessels. Tumor extends into muscularis propria, without necrosis.

FIGURE 2. Inflammatory pseudotumor in 26 -year-old man (Patient 7). Note spindle cells without atypia, loose matrix, and frequent plasma cells. FIGURE 3. Low-grade sarcoma in 87-year-old man (Patient 29). All sarcomas featured necrosis of the tumor (top and left) as it infiltrates the muscularis propria.

FIGURE 4. Low-grade sarcoma (also Patient 29). Nucleomegaly with prominent or double nucleoli (center) were useful diagnostic findings for lowgrade sarcoma. Also, neutrophils or eosinophils usually predominated in the inflammatory infiltrate, with plasma cells rarely seen.

FIGURE 5. Low-grade sarcoma (Patient 29). Myxoid degeneration was noted in 6 of 13 sarcomas; in this case, amphophilic material fills stromal clefts. Stroma in inflammatory pseudotumor was often edematous but not myxoid, and without dropout of cells.

FIGURE 6. Immunostaining for p53 showed nuclear reactivity in only rare cells in 9 of 15 inflammatory pseudotumors/postoperative spindle cell nodules (left). A constant feature in sarcoma was more intense nuclear reactivity involving $20-70 \%$ of cells (right).

1929, so these results may reflect lost immunogenicity. In PSCN and IP, p53 immunostaining was either weak $(1+)$, staining 2 to $60 \%$ of nuclei $(10$ of 14 cases) (Fig. 6), or was absent (4 of 14 cases). In IP/PSCN, 7 of 18 cases were weakly reactive for pan-cytokeratin, as were 3 of 8 leiomyosarcomas.
Cytokeratin-positive cases were also reactive with at least one mesenchymal marker and, as mentioned before, all had necrosis. Actins did not discriminate between benign and malignant tumor. $\alpha$-smooth muscle actin was positive in $43 \%$ of sarcomas, $63 \%$ of IP, and intermediate percent- 
TABLE 2. Immunohistochemical Reactivity in 30 Cases of Urinary Bladder Spindle Cell Tumor

\begin{tabular}{|c|c|c|c|c|c|}
\hline Antigen & $\begin{array}{l}\text { Inflammatory } \\
\text { Pseudotumor }\end{array}$ & $\begin{array}{l}\text { Postoperative Spindle } \\
\text { Cell Nodule }\end{array}$ & $\begin{array}{c}\text { Low-Grade } \\
\text { Leiomyosarcoma }\end{array}$ & $\begin{array}{c}\text { High-Grade } \\
\text { Leiomyosarcoma }\end{array}$ & Carcinoma \\
\hline Number of cases stained & 14 & 4 & 5 & 4 & 3 \\
\hline p53 protein & $7 / 10$ & $3 / 4$ & $5 / 5^{a}$ & $4 / 4^{a}$ & nd \\
\hline Pan-cytokeratin & $5 / 14$ & $2 / 4$ & $1 / 5$ & $2 / 3$ & $2 / 3$ \\
\hline Epithelial membrane antigen & $4 / 8$ & $1 / 3$ & $0 / 5$ & $1 / 3$ & $1 / 2$ \\
\hline Smooth muscle actin & $5 / 8$ & $2 / 4$ & $1 / 3$ & $2 / 4$ & $2 / 3$ \\
\hline Muscle-specific actin & $5 / 9$ & $2 / 3$ & $1 / 4$ & $0 / 1$ & $1 / 2$ \\
\hline Desmin & $3 / 11$ & $2 / 3$ & $0 / 5$ & $0 / 3$ & $0 / 3$ \\
\hline Vimentin & $10 / 10$ & $4 / 4$ & $5 / 5$ & $2 / 2$ & $1 / 1$ \\
\hline S-100 protein & $0 / 4$ & $0 / 3$ & nd & $0 / 2$ & nd \\
\hline
\end{tabular}

${ }^{a}$ Excludes two cases from 1928 and 1929, which were negative, probably reflecting lost immunogenicity.

nd, not done.

ages of PSCN and carcinoma. Three of 11 IP, 2 of 3 PSCN, and none of 8 sarcomas were reactive for desmin. In the IP with juxtamural urothelial carcinoma biopsied separately (Case 14), immunostains for cytokeratin were negative (unlike in the carcinoma) and positive for smooth muscle actin and vimentin.

Electron microscopy was performed in seven IP cases with available tissue, including the largest IP (Case 3 ) $-13 \mathrm{~cm}$, clinically reported as growing to $37.5 \mathrm{~cm}$ - and a PSCN with elevated mitotic rate
(Case 18). Findings were similar in IP and PSCN; carcinoma was definitely ruled out in all. Demonstrated features are myofibroblastic (Fig. 7) as opposed to smooth muscle (16): namely, presence of fibronexus junctions (extracellular fibronectin fibrils, intracellular actin), no true lamina external to the plasma membrane, abundant rough endoplasmic reticulum, and rare myofilaments and plasmalemmal caveolae.

Overall clinical and pathologic findings for each entity are summarized (Table 3).

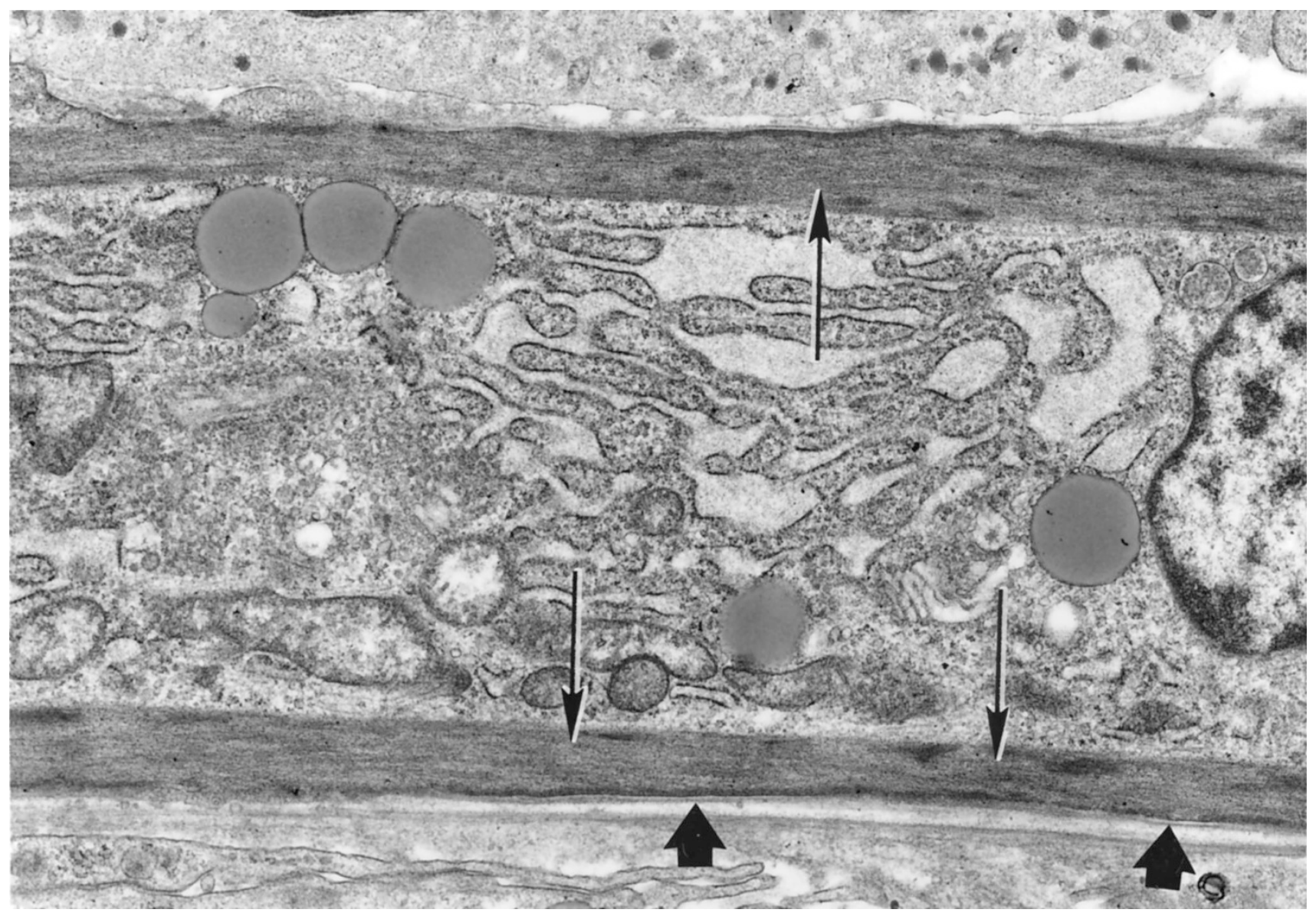

FIGURE 7. Inflammatory pseudotumor (Patient 16). Tumor cell showing myofibroblastic features of rough endoplasmic reticulum, peripheral smooth muscle myofilaments (long arrows), and fibronectin fibrils (short arrows) ( $\times 1600)$. (Micrograph courtesy of Dr. Alan Curry, Withington Hospital, Manchester, UK.) 


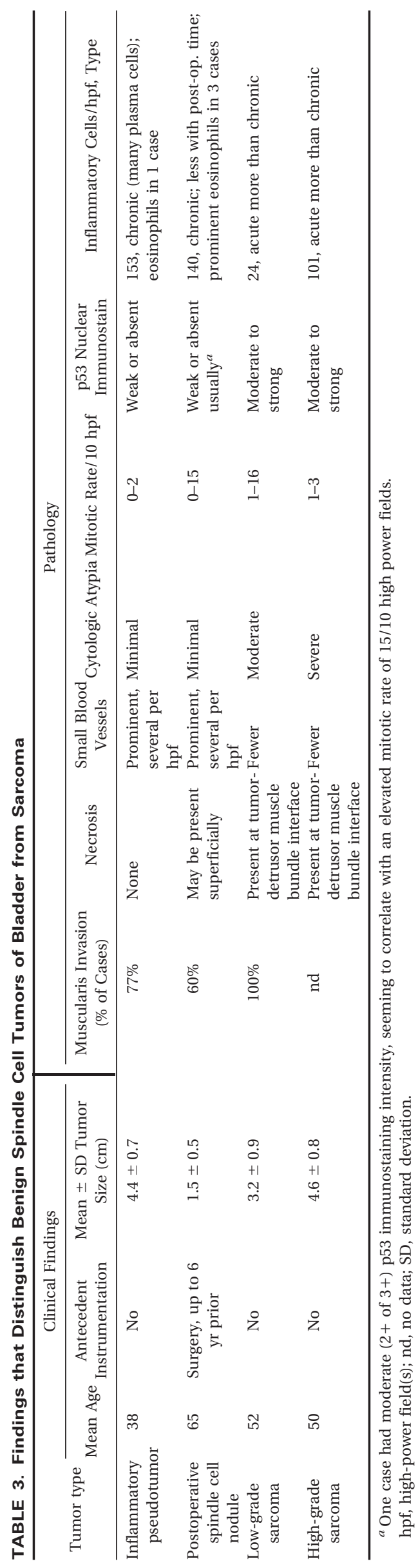

\section{DISCUSSION}

Necrosis or myxoid degeneration was key to the diagnosis of sarcoma, seen in all T2 cases; myxoid degeneration was previously noted in $60 \%$ of bladder leiomyosarcomas (17). Sarcoma also differed from IP by having moderate-severe nuclear atypia, 1 to 16 mitotic figures per $10 \mathrm{hpf}$ (rather than 0 to 2 , as described [6]), predominance of neutrophils over chronic inflammation, and metastatic potential.

Our data show that these histologic distinctions between IP and sarcoma correlated with different natural histories. Both were usually idiopathic, and except for one IP, were not associated with urothelial carcinoma. Both usually caused hematuria and, if large, obstructed the bladder outlet. The two entities overlapped in tumor size, male preponderance (in contrast to assertions about IP [6]), location within the bladder, $\mathrm{T}$ stage, and patient age. However, four of 12 followed-up patients with sarcoma had recurrence or death from fatal metastasis. The two metastatic tumors included one lowgrade and one high-grade case; both patients were at the extremes of age: 4 and 72 years. Eight other patients were cured by partial or radical cystectomy. Similarly, recurrence and death are reported in one (18) of 15 reported cases (18-21).

In contrast, no IP or PSCN have any documented instances of metastasis. IP tends to present with larger size than PSCN, and has seemingly limitless potential for local growth. We report the largest IP; untreated, it became $37.5 \mathrm{~cm}$ and caused death by obstruction, not metastasis. Seven prior studies traced IP outcome. Horn et al. followed three patients at 12 to 23 months (8); Ro et al. Followed eight patients at 24 to 108 months (9); Young and Scully followed one patient 42 months (10); Lakshmann followed one patient 4 months (11); Coyne followed one patient 9 months (12). Dietrick followed 2 patients 12 to 18 months (13); Jones et al. followed 10 new IP patients (and 1 with PSCN) 6 to 64 months (14). Therapy was size-dependent and was transurethral resection in 15 of the 26 patients, partial cystectomy in 10, and radical cystectomy in one. No tumors recurred or metastasized, suggesting that IP is benign. This finding also agrees with flow cytometry studies of IP that reveal diploid DNA content in 14 of 15 cases $(6,14,22,23)$. A limitation of our study is that the number of IP and PSCN cases precluded statistical analysis.

Separation of PSCN from IP is somewhat of an academic exercise, but PSCN differed by involving older patients (usually those undergoing resections of urothelial carcinoma), smaller average size, presence of eosinophils, and higher mitotic rate in some cases. The criterion that PSCN should be diagnosed only within 3 months of bladder surgery (7) seems too restrictive; lesions with distinctive PSCN histol- 
ogy in our study arose up to 13 months after surgery, at the prior surgical site. Thus we may consider reclassifying one case reported as IP in a 60year-old man, 15 months after transurethral resection of urothelial carcinoma (14), as PSCN. By analogy, the histology of post-transurethral resection granulomatous prostatitis is so distinctive that it can be diagnosed 7 years after surgery. A novel finding is one IP with synchronous urothelial carcinoma. The patient's age (72 years) and the tumor size were closer to the range seen in PSCN, but there was no prior instrumentation. The association of carcinoma with PSCN reflects a detection bias, because the latter by definition arises after bladder instrumentation. We found no association of urothelial carcinoma with sarcoma, suggesting independent etiologies.

Other studies have emphasized the role of prior inflammation, instrumentation, or surgery in IP or PSCN of bladder or ureter. Implicated associations include hysterectomy for leiomyoma (8), pyelonephritis (8), ruptured diverticulitis of the sigmoid colon with pseudotumor extending to the bladder (24), transurethral bladder resection (7), indwelling catheter (14) and cystitis (23, 25). In our study, antecedent conditions in one of 13 IPs were neurogenic bladder secondary to cerebrovascular accident, and, in all PSCN, bladder biopsy or transurethral resection. No patient with sarcoma had prior bladder instrumentation, and one had an apparent postradiation sarcoma after radiotherapy for rectal carcinoma.

Muscle marker reactivity in myofibroblasts has been characterized as variable (26). Prior reports on IP showed immunoreactivity of IP for actins in most cases and vimentin in all cases $(6,8,9,14,24)$, reflecting the myofibroblastic nature of the cells. Muscle-specific and $\alpha$-smooth muscle actin stains were reactive in some IP, PSCN, and sarcomas. Desmin was positive in 3 of 8 of our IP/PSCN, as in prior reports $(6,14,27,28)$, but in no sarcomas; likewise, Mills et al. reported 4 of 12 bladder leiomyosarcomas were desmin-negative (17). Because all our sarcomas were desmin-negative, were variably reactive for actins just like benign entities, and none had electron microscopy performed, we resisted the tendency to label them as leiomyosarcoma. It is conceivable that they are fibrosarcoma or malignant counterparts of IP. Actins were also positive in some carcinomas. The latter observation suggests that these carcinomas might be carcinosarcoma; similarly, $\alpha$-smooth muscle actin positivity was reported recently in 3 of 14 (29) and 1 of 1 (30) sarcomatoid bladder carcinomas and in 12 of 65 breast carcinomas (31). Desmin reactivity was seen in 3 of 14 bladder carcinomas, cases that may be true carcinosarcoma (29). In uterine smooth muscle neoplasms, p53 protein correlates with di- agnosis and separates patients into prognostic groups (32). Although we are uncertain that our 13 sarcomas are leiomyosarcoma, we found that p53 was the only immunostain tested that discriminated IP and PSCN (rare reactive cells) from sarcoma (more diffuse, moderate to strong reactivity).

Epithelial markers had minimal discriminant value. About half of IP and PSCN were cytokeratinpositive in our study, similar to cumulative reports of reactivity in 12 of 31 IP cases $(6,8-11,14,23-25$, 27 ) and 2 of 5 of PSCN cases $(10,14,28)$. Also, three of eight sarcomas were cytokeratin-positive, but all had necrosis and atypia. This is similar to reports of cytokeratin reactivity in $38 \%$ of leiomyosarcomas at various sites (33) and one case in bladder (34). The differential diagnostic potential of cytokeratin is further confounded by data from the spindle cell urothelial carcinoma series of Jones and Young (35) who found only 12 of their 19 carcinomas were positive for cytokeratin. Reactivity for epithelial membrane antigen, in our series, was noted in both benign and malignant tumors. Thus, even a substantial panel of the above immunostains may not conclusively distinguish pseudotumor/PSCN, sarcoma, or carcinoma. Fibronectin is reportedly specific for myofibroblasts (16), and perhaps should be studied in an IP/PSCN series like ours.

In conclusion, IP/PSCN and leiomyosarcoma of the bladder overlap in clinical and immunohistochemical findings but are histologically distinct, correlating with different natural histories. IP appears benign, not prone to metastasize, and is outside the spectrum of low-grade inflammatory sarcoma of bladder.

Acknowlegements: For patient follow-up, to urologists Drs. Eric L. Martin (Medford, OR), Stephen N. Zoretic (Emerson, NJ), Joel Rosenfeld (Atlanta), Carl Cascione (Gainesville, FL), and Richard E. Steinberger (Wichita, KS). For electron microscopy and contribution of cases, to pathologists Drs. B.P. Eyden, A. Curry, J. Coyne, and S. S. Banerjee (Manchester, U.K.), Dr. A. Mene (Blackburn, U.K.), Drs. D. S. Sareef and N. U. Hasan (Warrington, UK), and Dr. C. G. Janney (St. Louis).

\section{REFERENCES}

1. Selves J, Meggetto F, Brousset P, Voigt JJ, Pradere B, Grasset $\mathrm{D}$, et al. Inflammatory pseudotumor of the liver. Evidence for follicular dendritic reticulum cell proliferation associated with clonal Epstein-Barr virus. Am J Surg Pathol 1996;20: 747-53.

2. Aboulafia DM. Inflammatory pseudotumor causing small bowel obstruction and mimicking lymphoma in a patient with AIDS: clinical improvement after initiation of thalidomide treatment. Clin Infect Dis 2000;30:826-31.

3. Su LD, Atayde-Perez A, Sheldon S, Fletcher JA, Weiss SW. Inflammatory myofibroblastic tumor: cytogenetic evidence supporting clonal origin. Mod Pathol 1998;11:364-8. 
4. Sciot R, Dal Cin P, Fletcher CD, Hernandez JM, Garcia JL, Samson I, et al. Inflammatory myofibroblastic tumor of bone: report of two cases with evidence of clonal chromosomal changes. Am J Surg Pathol 1997;21:1166-72.

5. Lopez-Beltran A, Lopez-Ruiz J, Vicioso L. Inflammatory pseudotumors of the urinary bladder. Urol Int 1997;55:173-6.

6. Hojo H, Newton WA, Hamoudi AB, Qualman SJ, Wakasa H, Suzuki S, et al. Pseudosarcomatous myofibroblastic tumor of the urinary bladder in children: a study of 11 cases with review of the literature: an intergroup rhabdomyosarcoma study. Am J Surg Pathol 1995;19:1224-36.

7. Proppe KH, Scully RE, Rosai J. Postoperative spindle cell nodules of genitourinary tract resembling sarcomas: a report of eight cases. Am J Surg Pathol 1984;8:101-8.

8. Horn LC, Reuter S, Biesold M. Inflammatory pseudotumor of the ureter and urinary bladder. Pathol Res Pract 1997;193: 607-12.

9. Ro JY, El-Naggar AK, Amin MB. Pseudosarcomatous fibromyxoid tumor of the urinary bladder and prostate: immunocytochemical, ultrastructural, and DNA flow cytometric analyses of nine cases. Hum Pathol 1993;24:1203-10.

10. Young RH, Scully RE. Pseudosarcomatous lesions of the urinary bladder, prostate gland, and urethra. A report of three cases and review of the literature. Arch Pathol Lab Med 1987;111:354-8.

11. Lakshmanan Y, Wills ML, Gearhart JP. Inflammatory (pseudosarcomatous) myofibroblastic tumor of the bladder. Urology 1997;50:285-8.

12. Coyne JD, Wilson G, Sandhu D, Young RH. Inflammatory pseudotumor of the urinary bladder. Histopathology 1991; 18:261-4.

13. Dietrick DD, Kabalin JN, Daniels GF, Epstein AB, Fielding IM. Inflammatory pseudotumor of the bladder. J Urol 1992; 148:141-4.

14. Jones EC, Clement PB, Young RH. Inflammatory pseudotumor of the urinary bladder: a clinicopathological, immunohistochemical, ultrastructural, and flow cytometric study of 13 cases. Am J Surg Pathol 1993;17:264-74.

15. Fleming ID, Coper JS, Henson DE, Hutter RVP, Kennedy BJ, Murphy GP, et al., editors. American Joint Committee on Cancer. Cancer staging manual. 5th ed. Philadelphia: Lippincott-Raven; 1997.

16. Eyden BP. Brief review of the fibronexus and its significance for myofibroblastic differentiation and tumor diagnosis. Ultrastruct Pathol 1993;17:611-22.

17. Mills SE, Bova GS, Wick MR, Young RH. Leiomyosarcoma of the urinary bladder: a clinicopathologic and immunohistochemical study of 15 cases. Am J Surg Pathol 1989;13:480-9.

18. Caylor HD, Walters W. Leiomyosarcoma of the urinary bladder. J Urol. 1930;24:303-11.

19. Young RH, Proppe KH, Dickersin GR, Scully RE. Myxoid leiomyosarcoma of the urinary bladder. Arch Pathol Lab Med 1987;111:359-62.

20. Wick MR, Brown BA, Young RH, Mills SE. Spindle cell proliferations of the urinary tract: an immunohistochemical study. Am J Surg Pathol 1988;12:379-89.
21. Swartz DA, Johnson DE, Ayala AG, Watkins DL. Bladder leiomyosarcoma: a review of 10 cases with 5 -year followup. J Urol 1985;133:200-2.

22. August CZ, Khazoum SG, Mutchnik DL. Inflammatory pseudotumor of the bladder: a case report with DNA content analysis. J Urol Pathol 1993;1:211-6.

23. Ro JY, Ayala AG, Ordonez NG, Swanson DA, Babaian RJ. Pseudosarcomatous fibromyxoid tumor of the urinary bladder. Am J Clin Pathol 1986;86:583-90.

24. Saito $\mathrm{M}$, Watanabe $\mathrm{N}$, Abe $\mathrm{B}$, Matsui K. Inflammatory pseudotumor of the urinary bladder and sigmoid colon. Urol Int 1999;62:119-21.

25. Roth JA. Reactive pseudosarcomatous response in urinary bladder. Urology 1980;16:635-7.

26. Mentzel T, Dry S, Katenkamp D, Fletcher CDM. Low-grade myofibroblastic sarcoma: analysis of 18 cases in the spectrum of myofibroblastic tumors. Am J Surg Pathol 1998;22: 1228-38.

27. Sonobe H, Okada Y, Sudo S, Iwata J, Ohtsuki Y. Inflammatory pseudotumor of the urinary bladder with aberrant expression of cytokeratin: report of a case with cytologic, immunocytochemical and cytogenetic findings. Acta Cytol 1999; 43:257-62.

28. Huang W-L, Ro JY, Grignon DJ, Swanson D, Ordonez NG, Ayala AG. Postoperative spindle cell nodule of the prostate and bladder. J Urol 1990;143:824-6.

29. Ikegami H, Iwasaki H, Ohjimi Y, Takeuchi T, Ariyoshi A, Kikuchi M, et al. Sarcomatoid carcinoma of the urinary bladder: a clinicopathologic and immunohistochemical analysis of 14 patients. Hum Pathol 2000;31:332-40.

30. Mazzucchelli L, Kraft R, Gerber H, Egger C, Studer UE, Zimmermann A. Carcinosarcoma of the urinary bladder: a distinct variant characterized by small cell undifferentiated carcinoma with neuroendocrine features. Virchows Arch A Pathol Anat Histopathol 1992;421:477-83.

31. Santini D, Ceccarelli C, Taffurelli M, Pileri S, Marrano D. Differentiation pathways in primary invasive breast carcinoma as suggested by intermediate filament and biopathological marker expression. J Pathol 1996;179:386-91.

32. Layfield LJ, Liu K, Dodge R, Barsky SH. Uterine smooth muscle tumors: utility of classification by proliferation, ploidy, and prognostic markers versus traditional histopathology. Arch Pathol Lab Med 2000;124:221-7.

33. Iwata J, Fletcher CDM. Immunohistochemical detection of cytokeratins and epithelial membrane antigen in leiomyosarcoma: a systematic study of 100 cases. Pathol Int 2000;50: $7-14$.

34. Kunze E, Theuring F, Kruger G. Primary mesenchymal tumors of the urinary bladder: a histological and immunohistochemical study of 30 cases. Pathol Res Pract 1994;190:31132 .

35. Jones EC, Young RH. Myxoid and sclerosing sarcomatoid transitional cell carcinoma of the urinary bladder: a clinicopathologic and immunohistochemical study of 25 cases. Mod Pathol 1997;10:908-16. 